\title{
CONFLITOS SOCIOAMBIENTAIS URBANOS: UM ESTUDO PROSPECTIVO NA REGIÃO METROPOLITANA DE SÃO PAULO
}

\section{URBAN ENVIRONMENTAL CONFLICT: A PROSPECTIVE STUDY IN THE METROPOLITAN REGION OF SÃO PAULO}

\section{Mauro Silva Ruiz}

Doutor em Geografia (Planejamento em Recursos Naturais) pela Universidade do Sul de Illinois em Carbondale, EUA.

Docente do Programa de Mestrado em "Cidades Inteligentes e Sustentáveis" e Diretor do Programa de Mestrado Profissional em "Gestão Ambiental e Sustentabilidade" da Universidade Nove de Julho UNINOVE, Brasil.

E-mail: maurosilvaruiz@gmail.com

José Maria Bernardelli Jr.

Mestre em Gestão Ambiental e Sustentabilidade pela Universidade Nove de Julho - UNINOVE, Brasil. Programa de Mestrado Profissional em Gestão Ambiental e Sustentabilidade - Universidade Nove de Julho.

E-mail: jmbjr21@gmail.com

\section{Cristiano Capellani Quaresma}

Doutor em Geografia pela Universidade Estadual de Campinas - Unicamp, Brasil.

"Docente do Programa de Mestrado em Cidades Inteligentes e Sustentáveis e no curso de Engenharia Civil" da Universidade Nove de Julho- UNINOVE.

E-mail: mauecologia@yahoo.com.br

\section{Maurício Lamano Ferreira}

Doutor em Ciências pelo Centro de Energio Nuclear na Agricultura da Universidade de São Paulo USP, Brasil.

Docente do Programa de Mestrado em "Cidades Inteligentes e Sustentáveis" e no curso de "Engenharia Civil" da Universidade Nove de Julho.

E-mail: mauecologia@yahoo.com.br 


\section{CONFLITOS SOCIOAMBIENTAIS URBANOS: UM ESTUDO PROSPECTIVO NA REGIÃO METROPOLITANA DE SÃO PAULO}

\section{RESUMO}

Regiões metropolitanas em nível mundial vêm enfrentando mudanças significativas em seus processos de uso e ocupação do solo tornando-as palco de conflitos socioambientais crescentes. Considerando que esses embates vêm ganhando expressão em regiões densamente ocupadas em nosso país, delineou-se como objetivo deste estudo verificar suas origens e formas de manifestação na Região Metropolitana de São Paulo (RMSP) com vistas a entendêlos, classificá-los e analisá-los. A questão norteadora da pesquisa foi: quais as origens dos principais conflitos socioambientais que se manifestam na Região Metropolitana de São Paulo e como eles podem ser classificados e analisados à luz da literatura existente? Como metodologia, este trabalho baseou-se em revisão bibliográfica e análise documental. Como resultado, constataram-se cinco origens ou formas de manifestação mais comuns, por vezes sobrepostas, relacionadas a: (i) urbanização periférica e desigual; (ii) operação urbana; (iii) ocupação irregular em áreas protegidas; (iv) danos e passivos ambientais; e (v) degradação de recursos hídricos. Observou-se que, não raro, suas origens e manifestações relacionam-se a deficiências na aplicação e gestão de políticas públicas. Além disso, constatou-se também uma diversidade considerável de abordagem desses conflitos, o que impõe desafios para organizar esta temática de acordo com um ou mais princípios teóricos.

Palavras-Chave: Meio Ambiente. Conflitos Socioambientais. Regiões Metropolitanas. Planejamento Urbano e Regional. 


\title{
URBAN ENVIRONMENTAL CONFLICT: A PROSPECTIVE STUDY IN THE METROPOLITAN REGION OF SÃO PAULO
}

\begin{abstract}
Metropolitan areas worldwide are facing significant changes in its land use and occupation processes making it a proper scenario for increasing environmental conflicts. Whereas these conflicts are gaining expression in densely occupied areas in Brazil, the objective of this study was to verify their origin and different ways of manifestation in the Metropolitan Region of São Paulo (MRSP) in order to understanding, classifying and analyzing them. Thus, we drove the follow question: What are the origins of the main environmental conflicts that arise in the Greater São Paulo and how they can be sorted and analyzed in the light of the existing literature? For methodology, this work was based on a bibliographic review and documental analyses. As a result, five sources or common forms of manifestation were found, even overlapping in some cases, related to: (i) peripheral and uneven urbanization; (ii) urban operation; (iii) irregular settlements in protected areas; (iv) environmental damage and liabilities; and (v) degradation of water resources. It was observed that, often, the conflict origins and manifestations are related to deficiencies in the implementation and management of public policies. In addition, there was also a considerable diversity of approach to these conflicts, which creates challenges to organize this issue in accordance with one or more theoretical principles.
\end{abstract}

Keywords: Environment.Environmental Conflicts.Metropolitan Regions.Urban Planning. 


\section{INTRODUÇÃO}

De acordo com dados apresentados no relatório elaborado pelo Departamento de Assuntos Econômicos e Sociais das Nações Unidas o percentual da população mundial vivendo em áreas urbanas passa de 30\%no ano de 1950 para 54\% no ano de 2014 (UN, 2015).Esta rápida evolução, associada muitas vezes à falta de planejamento, especialmente em países não desenvolvidos, resultou em transformações significativas, marcadas pela degradação ambiental e pela exclusão sócio espacial, bem como pelo surgimento de conflitos socioambientais de alta complexidade em várias regiões metropolitanas ao redor do mundo.

Segundo Nobre, Young, Saldiva, Nobre, Silva e Lombardo (2010), existiam 21 mega cidades com população acima de 10 milhões de habitantes em 2004, sendo duas no Brasil, a saber, as regiões metropolitanas de São Paulo e do Rio de Janeiro. Tais regiões, de acordo com o Instituto Brasileiro de Geografia e Estatística -IBGE (2010), apresentaram, em 2010,os valores de população absoluta de 19.683.975 e 11.835.708, respectivamente.Devido às suas grandes áreas e às suas elevadas densidades populacionais, tais regiões impõem enormes desafios aos urbanistas, prefeitos, administradores e a todos os responsáveis pelo fornecimento de serviços básicos e de infra estrutura.Um dos desafios da metropolização mundial reside no enfrentamento e busca de soluções aos vários tipos de conflitos socioambientais que emergem nas regiões densamente ocupadas e conturbadas.

Originalmente, os conflitos socioambientais eram denominados simplesmente de conflitos ambientais, embora não se encontre uma definição clara, precisa e única para este termo. O que se observa é uma proliferação de conceitos nem sempre precisos, o que estimula uma polissemia entre os termos utilizados (Acselrad, 2004).

No que se refere aos conflitos socioambientais urbanos, Dias (2000) argumenta que tal denominação ganhou expressão após a Conferência das Nações Unidas para o Meio Ambiente, a Rio 92, para designar os conflitos sociais urbanos. Segundo o autor, o meio ambiente urbano, cada vez mais pressionado pela ação antrópica, passa a refletir os conflitos sociais e políticos, principalmente onde o poder público não acena com soluções para atender às necessidades dos cidadãos.

Tais conflitos socioambientais, ligados às relações de poder estabelecidas entre os diversos atores sociais (pessoas, grupos, comunidades, empresas), bem como às formas de apropriação e transformação do espaço urbano, manifestam-se, no contexto urbano, quando os

Revista de Gestão e Secretariado-GeSec, São Paulo, v. 7, n. 2, p 21-54,mai./ago. 2016. 
fatores que os causam afetam de alguma forma a qualidade de vida da população situada no entorno das atividades ou situações que os geram.

Como exemplos de situações que desencadeiam tais conflitos, podem ser citadas: (i) a urbanização especulativa e desigual (Silva, 2007; Meyer, 2004; Negri, 1996) que dissemina moradias de risco em encostas e próximas a mananciais, intensificando as demandas judiciais por habitação segura e saneamento sobre o poder público (Cunha, 2001); (ii) a ocupação ou desocupação de uma área (Laschefski\& Costa, 2008); (iii) atividades poluidoras afetando comunidades e populações (Côrtes, Alves Filho, Ruiz, Teixeira, 2011; Instituto Brasileiro de Análises Sociais e Econômicas, 2003; Jacobi, 1995). Baechler (1998) menciona que os resultados do Swiss Peace Institute'sEnvironmentand Conflict (Encop) em quatro continentes mostraram que a deterioração da qualidade ambiental é um dos fatores que pode acentuar os problemas sociais existentes em regiões ou localidades. Tais resultados destacam que os conflitos socioambientais se manifestam como conflitos políticos, sociais, econômicos, étnicos, religiosos ou territoriais, ou seja, são conflitos tradicionais induzidos pela degradação ambiental.

O padrão atual de urbanização dispersa, em que bairros tipicamente industriais mudam suas configurações à medida que as indústrias migram para outras localidades, originando nesses bairros antigos as chamadas "novas centralidades" (Maricatto, 2003; Castro, 2009; Negri, 1996), também tem resultado em situações conflituosas envolvendo áreas contaminadas com resíduos industriais e combustíveis. Na Região Metropolitana de São Paulo (RMSP), principalmente na Grande $\mathrm{ABC}$, são diversos os casos de conflitos relacionados a esses passivos ambientais, com legados contenciosos que poderão perdurar por décadas sem uma solução que possa satisfazer a todas as partes envolvidas (Araujo \& Gunther, 2009).

A ausência de publicações que tratem de conflitos sócio ambientais de uma forma ampla, caracterizando de forma agregada suas diferentes formas de manifestação em regiões metropolitanas do estado de São Paulo, se apresenta como o problema de estudo em questão.

Segundo Cimba lista (2002), qualquer que seja a ótica, a preocupação com a gestão de conflito implica agir levando-se em conta suas características e dominar suas origens e consequências, assim, a questão de pesquisa que se coloca é: quais as origens dos principais conflitos socioambientais que se manifestam na Região Metropolitana de São Paulo e como eles podem ser classificados e analisados à luz da literatura existente? 
Com base na revisão da literatura, este trabalho tem por objetivo analisar a origem e formas de manifestação de conflitos socioambientais em regiões metropolitanas, com ênfase nos mecanismos de resolução mais comuns adotados na Região Metropolitana de São Paulo (RMSP). Considera-se que os resultados desta análise poderão ser relevantes para gestores de conflitos, principalmente os da esfera pública, preocupados com a adoção de medidas que levem em conta tanto suas origens como suas consequências.

\section{REVISÃO BIBLIOGRÁFICA}

\section{Caracterização de Conflitos Ambientais}

O levantamento bibliográfico indicou a existência de uma quantidade expressiva de publicações sobre conflitos ambientais, em nível nacional e internacional, mostrando que o tema vem recebendo atenção considerável nos últimos anos.

Em relação aos estudos acadêmicos, Alonso e Costa (2002), destacam as aplicações das teorias construtivistas da Sociologia, especialmente de Hannigan (1995), para o caso brasileiro. Fuks (1997) recorre ao arsenal de conceitos dessa linha teórica - idiomas retóricos, repertórios discursivos e pacotes interpretativos - para argumentar que os atores constroem certas dimensões sociais como problemas ambientais no interior do espaço público definido como arena argumentativa. Os conflitos configuram, então, em torno dessas definições, diz ele, apresentando um estudo de caso como demonstração.

Dahrendorf (1963) que estudou conflitos sob a ótica sociológica destacou que: "todas as sociedades produzem constantemente em si antagonismos que não nascem casualmente nem podem ser arbitrariamente eliminados”. Essa afirmação tem certa relação com a visão expressa pelo Instituto Brasileiro de Análises Sociais e Econômicas (2003) de que esses conflitos são sintomáticos do modo como o meio ambiente é apropriado e incorporado pelos diferentes agentes econômicos e sociais, públicos ou privados, resultando em repercussões negativas sobre as populações menos favorecidas, que são as que mais sofrem as consequências da degradação ambiental resultante dessa apropriação. Ao tratarem da questão, introduzem os conceitos de conflitos socioambientais e de injustiça ambiental relacionando-os às lutas sociais que concernem à relação das populações com o ambiente. Como exemplo, destacam embates de comunidades de pescadores afetados por poluição 
hídrica oriunda de atividades industriais na Baixada Fluminense, RJ.

Matthew,Gauline McDonald (2003) tratam alguns conflitos sob uma perspectiva na linha antropológica enfatizando a Ecologia Social. Esses autores relacionam conflitos com condições de estresse ambiental e examinam o momento em que este estresse supostamente supera os mecanismos de adaptação social e, consequentemente, contribui para a deflagração do conflito. Enfatizam que, para que haja um bom entendimento dos efeitos sociais causados por mudanças ambientais, é necessário que o tempo de análise seja bem dilatado. Os autores destacam também que enquanto tem havido um esforço considerável entre pesquisadores de segurança ambiental em desenvolver uma tipologia detalhada que demonstre que nem todos os conflitos são iguais, também tem sido frequente o entendimento geral de que independentemente do tipo de conflito, todos os conflitos são maus. Por fim, os autores ponderam, no entanto, que enquanto conflitos podem ser maus em alguns sentidos, em outros também podem ser vitais e, às vezes, necessários.

\section{Caracterização de Conflitos na RMSP}

Jacobi (2006) enfatiza que uma crise ambiental de grandes proporções assola as metrópoles brasileiras, gerando injustiças ambientais como resultado de políticas administrativas e práticas de gestão equivocadas ou inadequadas por parte dos responsáveis. A periferia das cidades não é normalmente provida de serviços urbanos básicos, fato que tem promovido a sua ocupação por grupos de renda menos privilegiados. Essa situação cria um palco fértil para o surgimento de conflitos ambientais, particularmente no caso das ocupações de várzeas, de encostas de morros e de mananciais de abastecimento como, por exemplo, das represas Billings e Guarapiranga, na Região Metropolitana de São Paulo. Os conflitos sócio ambiental relacionados ao adensamento humano rumo aos contrafortes da Cantareira evidenciam os efeitos da expansão da malha urbana sobre áreas naturais.

Kowaricke Marques (2012) apontam que mesmo produzidos fora dos padrões técnicos recomendáveis e construídos ao longo de anos, a moradia popular, o loteamento clandestino e as favelas paulistas, na medida do possível, apresentam hoje melhor qualidade habitacional do que nas décadas passadas. Os autores destacam também como consequência desses diversos processos contraditórios, a existência de uma intensa heterogeneidade territorial da cidade, inclusive nos espaços periféricos, com a presença de múltiplas formas de

Revista de Gestão e Secretariado-GeSec, São Paulo, v. 7, n. 2, p 21-54,mai./ago. 2016. 
segregação e pobreza nas periferias paulistas. Dessa forma, pode-se dizer que a periferia da metrópole continua sendo um palco fértil para a ocorrência de conflitos socioambientais.

\section{Múltiplas Visões e Possibilidades de Abordagens de Conflitos Ambientais}

Preocupados com o entendimento dos conflitos com vista a buscar soluções, Bobbio, Matteuccie Pasquino (1986) destacam a importância de conhecer como eles surgem se manifestam e ganham expressão. Enfatizam que para compreendê-los é necessário, num primeiro momento, analisar os agentes em embate e o meio físico e institucional em que aparecem.

De acordo com Little (2001), a análise dos conflitos socioambientais deverá levar em consideração os contextos ambiental, geográfico e histórico, os quais estão relacionados às diferentes formas de produção dos grupos sociais.

Ainda segundo esse autor, a resolução de conflitos socioambientais é uma tarefa difícil devido à complexidade e à profundidade das divergências, preferindo-se assim falar em tratamento desses conflitos em vez de sua resolução, pois:

para resolvê-los de forma definitiva, as suas múltiplas causas teriam de ser eliminadas e as divergências existentes entre as partes solucionadas pacífica, voluntária e consensualmente. Além do mais, os processos de degradação de mundo natural necessitariam de ser cessados para que a solução fosse social e ambiental. Esses requerimentos, embora possíveis de se conseguir, raras vezes acontecem na prática. (Little, 2001).

Little (2004), considerando a importância da análise etnográfica propõe que:

é possível abordar um conflito a partir de sua análise etnográfica. Primeiro com a identificação do foco central do conflito, considerando-se que haja conflitos em três grandes blocos: controle sobre os recursos naturais; impactos (sociais ou ambientais) gerados pela ação humana; e ideologias. Também é essencial a identificação e análise dos principais atores sociais envolvidos e suas interações e, ainda, a descrição das suas cotas de poder, sejam poderes formais e informais. (Little, 2004).

As questões que envolvem à resolução de conflitos ambientais são bastante complexas e além de envolver diversos atores, envolvem também diferentes esferas da sociedade, conforme mostra o quadro 1.

Revista de Gestão e Secretariado -GeSec, São Paulo, v. 7, n. 2, p 21-54,mai./ago. 2016. 
Quadro 1: Conflitos e resoluções na perspectiva de diferentes autores.

\begin{tabular}{|c|c|}
\hline Autor (ano) & Conflito/Resolução \\
\hline Roundeu (1996) & $\begin{array}{l}\text { Ao tratar de conflitos nas organizações, o autor destaca que o simples fato de se } \\
\text { preocupar com a gestão do conflito implica agir tendo em conta todas as } \\
\text { características de um conflito e de dominar tanto suas origens como suas } \\
\text { consequências. }\end{array}$ \\
\hline Bredariol (2004) & $\begin{array}{l}\text { O autor afirma que não há uma tradição em negociação de conflitos } \\
\text { socioambientais em nosso país, mas que eles aparecem na literatura como } \\
\text { bases para a construção da política ambiental. }\end{array}$ \\
\hline Braga Neto (2011) & $\begin{array}{l}\text { O autor menciona que nas negociações de conflitos ambientais, o Ministério } \\
\text { Público Federal e Estadual, órgãos estaduais e municipais ligados ao meio } \\
\text { ambiente têm desempenhado importante papel, ao priorizarem o diálogo } \\
\text { objetivando a cooperação entre as partes envolvidas. Seu objetivo é construir } \\
\text { compromissos a serem efetivamente cumpridos, por estarem identificados os } \\
\text { interesses reais de todos os envolvidos, dentro dos limites impostos pela norma } \\
\text { jurídica e adequados à prioridade de preservar o meio ambiente. }\end{array}$ \\
\hline Costa (2011) & $\begin{array}{l}\text { Por sua vez, o autor considera que, no atual contexto brasileiro, apenas o Estado } \\
\text { e alguns segmentos da sociedade têm o privilégio de agir em nome daquilo que } \\
\text { eles entendem como meio ambiente e dano ambiental. Em decorrência disso, } \\
\text { segundo o autor, o debate público está restrito àdisputa no campo simbólico, } \\
\text { concentrada a uma parcela pequena da sociedade. }\end{array}$ \\
\hline Valverde e Kiyotani (1986) & $\begin{array}{l}\text { Ao estudarem a mineração em áreas urbanas, os autores mencionam que a } \\
\text { coexistência nem sempre pacífica da mineração com o desenvolvimento urbano } \\
\text { em várias regiões do mundo tem sido objeto de estudos desde a década de } \\
\text { 1960. Os autores destacam que este problema em São Paulo começou a se } \\
\text { avolumar com a urbanização crescente em face do desenvolvimento industrial, } \\
\text { o que exigia maior demanda de substâncias minerais, ocupava e exigia áreas } \\
\text { onde a mineração tinha se instalado. }\end{array}$ \\
\hline
\end{tabular}

Fonte: Elaborado pelos autores.

A literatura sobre situações de conflitos entre empresas e/ou governos com o público propõe o entendimento da agressividade do público, em relação a uma situação de risco, como uma resposta à dor ou ameaça de dor, real ou imaginária. Nessa interpretação, a agressividade - toda reação que escapa ao diálogo, podendo manifestar-se em campanhas de opinião, boicotes e ações judiciais - é uma defesa diante de uma ameaça, cuja percepção pode ser adequada ou não (Cunha, 2006).

$\mathrm{Na}$ literatura internacional observou-se incidência crescente de embates ambientais envolvendo áreas contaminadas de várias naturezas e também conflitos socioambientais relacionados a colapsos e subsidência decorrentes de sobrecarga pela expansão urbana, bombeamento de águas subterrâneas e mineração subterrânea de carvão.

Situações conflituosas envolvendo áreas contaminadas em adensamentos urbanos têm sido cada vez mais frequentes no Brasil. Nesses casos, por serem relacionadas a passivos ambientais cujas origens remontam há décadas, quando inexistia legislação específica sobre o 
assunto, a atribuição de responsabilidades no âmbito jurídico não é algo simples. Um aspecto delicado nesses casos, também é a comunicação de risco à população, que às vezes não dispõe de informações claras sobre a periculosidade dos contaminantes presentes nos entornos dos locais em que habitam. Um caso típico, é o da contaminação por organoclorados da rua Cápua, em Santo André - SP, na qual o Instituto de Pesquisas Tecnológicas desenvolveu estudos técnicos visando identificar as melhores alternativas tecnológicas para descontaminação(Ruiz,Yu, Martins \& Goncalves, 2012). Conflitos relacionados à subsidência induzida por atividades antrópicas também ocorrem em nível mundial. Segundo Bastos e Freitas (1999), a subsidência pode resultar da adição de líquidos no solo ou da extração de sólidos com alto teor de água quando estes são drenados. Os Fens, na Inglaterra, os Everglades, na Flórida, e os Polders, na Holanda, são exemplos de grandes áreas que sofreram subsidência do solo após drenagem.

A expansão urbana sobre áreas instáveis do ponto de visto geológico-geotécnico e por extração de água subterrânea tem sido objeto de estudo na cidade do México e em outras como Nova Orleans, Londres, Bangcoc, Veneza, Houston, Galveston, Tóquio e Shangai (Dolan \& Goodel, 1986). Nesses casos, a subsidência ocorre em função da expulsão lateral de água por sobrecarga ou pelo rebaixamento do lençol freático provocado pelo bombeamento da água.

Conflitos associados à subsidência de minas antigas de carvão afetando cidades e vilas também têm sido comuns em estados com tradição mineira nos EUA como Illinois, Pensilvânia, Kentucky, Indiana, West Virginia e Alabama. No estado de Illinois, merecem destaque os estudos de Bauer, Trent eDumontelle (2006); Dumontelle, Bradford, Bauer eKilley (1981); Mavrolase Schechtman (1981). No Brasil, Ruiz, Correa, Gallardo\& Sintoni (2014) e Coulon (1990) analisaram os impactos de subsidência de minas de carvão que resultaram em situações conflituosas em Criciúma - SC.

Nickume Easter (1994), ao analisarem a crise de água que está emergindo na borda do Pacífico, referem-se a Bangcoc na Indonésia, Beijing na China e Madras na Índia, que apresentam déficits de abastecimento, e a Seoul na Coreia do Sul e Osaka e Yahagi-Na goya no Japão que têm excedentes de abastecimento. Destacam que o consumo de água está aumentando nas áreas urbanas, em função do afluxo populacional, gerando escassez e conflitos. Em um dos casos que os autores analisaram no Japão foi mencionado o conflito por água entre agricultores e a indústria automobilística (Toyota). Por fim, eles alertam que 
embora os conflitos envolvendo oferta e demanda de água nessas cidades sejam crescentes, as soluções têm sido apenas provisórias.

Como formas possíveis de gerenciar conflitos relacionados a impactos, danos e passivos ambientais, Westman (1985) aponta a gestão preventiva (antecipação de conflitos) e a mediação. Adicionalmente, indica como outras possíveis formas de resolução desses embates, acordos entre as partes; formulação e implantação de políticas públicas (p. ex.: zoneamento); e decisões judiciais.

\section{MÉTODO DE PESQUISA}

Tendo em vista que a análise de informações sobre conflitos sócios ambientais urbanos geralmente se apresenta de forma dispersa e sob abordagens com perspectivas variadas na literatura pertinente ao tema, optou-se, como metodologia para o presente trabalho, pela revisão documental e bibliográfica. Para tanto, foram analisados artigos científicos, monografias, dissertações de mestrado e documentos diversos, tais como relatórios de pesquisa e textos disponíveis na internet. A identificação dos conflitos analisados se deu por consultas a artigos publicados em revistas indexadas e em cadernos e brochuras acadêmicas.

A partir dessas considerações, o estudo em questão tem um caráter prospectivo, pois busca estabelecer um entendimento inicial sobre as origens e manifestações dos conflitos sócio ambientais num contexto regional, bem como apontar medidas e ações no sentido de contornar seus impactos ou problemas decorrentes. Para auxiliar nas ações metodológicas foi utilizada bibliografia específica (Lakatos \& Marconi, 2007; Severino, 2007; Cervo \& Bervian, 1996; Gil, 1995).

Adicionalmente, foram utilizadas também três das quatro tipologias de conflitos estabelecidas por Little (2001), quais sejam: 1.conflitos em torno do controle sobre os recursos naturais; 2.conflitos em torno dos impactos ambientais e sociais gerados pela ação humana e natural; e 3.conflitos em torno do uso dos conhecimentos ambientais.

\section{ANÁLISE E DISCUSSÃo}

A análise documental e bibliográfica permitiu a identificação de diferentes Revista de Gestão e Secretariado-GeSec, São Paulo, v. 7, n. 2, p 21-54,mai./ago. 2016. 
perspectivas de abordagem dos conflitos socioambientais na RMSP em quatro tópicos detalhados a seguir.

\section{Abrangência e Amplitude Conceitual}

São vários os conceitos de conflitos socioambientais existentes na literatura como mostra o Quadro 2.

Quadro 2: Conceitos de conflitos aplicáveis na área ambiental indicando os autores e/ou instituições que os utilizaram

\begin{tabular}{|l|}
\hline Conceito \\
\hline São embates entre grupos sociais em função de seus distintos modos de inter- \\
relacionamento ecológico, isto é, com seus respectivos meios sociais e naturais. \\
Especificamente é quando o cerne do conflito gira em torno das interações ecológicas.
\end{tabular}

Especificamente é quando o cerne do conflito gira em torno das interações ecológicas.
Autor / Instituição

Secretaria de Meio

Ambiente do Estado de

São Paulo (2009);

Laschefskie Costa (2008).

Cunha (2006)

São disputas entre grupos humanos, ligados aos diferentes usos que eles fazem dos
recursos ambientais. São fenômenos complexos, onde estão em questão o mundo biofísico e sua dinâmica, as relações sociais existentes em cada sociedade, e as interações entre ambas estas esferas.

São aqueles que envolvem grupos de interesse com modos diferenciados de apropriação, uso e significação do território, tendo origem quando pelo menos um desses grupos tem a continuidade das formas que adotam de apropriação do meio ameaçada pelos impactos indesejáveis decorrentes de práticas de outros grupos. Podem derivar da disputa por apropriação de uma mesma base de recursos ou de bases distintas, mas interconectadas por interações ecossistêmicas mediadas pela atmosfera, solo e águas. Em geral, têm como palco uma mesma unidade territorial compartilhada por um conjunto de atividades cujo acordo simbólico é rompido em função da denúncia dos efeitos indesejáveis que a atividade de um dos agentes produz sobre as condições materiais do exercício das práticas de outros agentes. Ex.: Rompimento de dique de lagoa de efluentes industriais, em período chuvoso, afetando rio e comunidade de pescadores.

São aqueles nos quais os embates se dão entre múltiplos agentes ou grupos sociais, em interação entre si, e com seu meio biofísico, em face dos seus modos distintos de interrelacionamento ecológico.

Aplica-se uma ampla gama de situações relacionadas com questões ambientais e que envolve situações de denúncias partindo de iniciativas individuais as quais tornam as agressões ambientais visíveis na esfera pública. Sob essa denominação podem ser consideradas situações de risco iminente em que duas ou mais partes podem ser afetadas pelos danos causados pela ação humana. A geração de ruídos por alguma atividade industrial, acima dos limites toleráveis pela legislação, causando incômodos ou tendo efeito negativo sobre a saúde da comunidade vizinha ilustra este conceito.

São conflitos sociais que têm elementos da natureza como objeto e que expressam as relações de tensão entre interesses coletivos/espaços públicos versus interesses privados/tentativa de apropriação de espaços públicos.

Uma forma de interação entre indivíduos, grupos, organizações e coletividade que
Instituto Brasileiro de Análises Sociais e Econômicas (2003);Acselrad, 2004; Costa (2011)

Little (2004)

Maciel (2002)

Carvalho

(2005);

Cunha (2001)

Bobbio, Matteuccie 


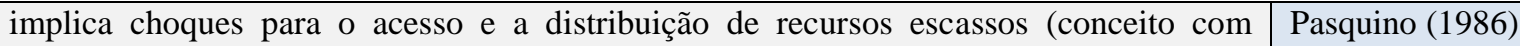
conotação mais social e política, mas que também se aplica a questões ambientais).

Fonte: Elaborado pelos autores.

A análise do Quadro 2 permite identificar pontos relevantes dos conceitos de conflitos aplicáveis na área ambiental, quais sejam:

- envolvem a interação de múltiplos grupos de interesse;

- essa interação pode se traduzir em disputas pelo acesso e uso de recursos naturais (sujeitos a situações de escassez relativa) num mesmo espaço territorial;

- essas disputas podem relacionar-se à forma como cada agente em embate enxerga a importância e/ou se apropria dos recursos naturais disponíveis naquele espaço;

- essas disputas também podem resultar de denúncias envolvendo danos ambientais oriundos de poluição e percepção de risco de possíveis acidentes.

\section{Consolidação do Tema como Campo de Estudo}

Os conflitos socioambientais começaram a ganhar evidência mundial a partir de 1978, com a veiculação de informações sobre o Love Canal nos EUA (Phillips, Hung, \& Bosela, 2007; Formosinho, Pio, Barros \& Cavalheiro, 2002; Wentz, 1995), área contaminada por resíduos químicos localizada nas imediações das Cataratas do Rio Niágara, que posteriormente foi ocupada por residências gerando problemas de saúde na população. $\mathrm{O}$ assunto tornou-se mais frequente na mídia a partir da década de 1980, em função dos grandes acidentes ambientais registrados em vários países como Vila Socó no Brasil, Bhopal na Índia, Seveso na Itália (Freitas, Porte \& Gomez, 1995; Ritter, Solomon\&Forget, 1995), dentre outros. No Brasil, embora várias situações ambientais conflituosas ocorressem há anos, o assunto começou a ser tratado com mais atenção somente após a realização da Conferência Mundial para o Meio Ambiente e Desenvolvimento no Rio de Janeiro mundialmente conhecida como Eco-92.

No que concerne aos conflitos socioambientais metropolitanos, a análise desses embates demanda um breve retrospecto do rápido crescimento populacional e sua relação com a expansão industrial nas grandes cidades brasileiras. A década de 1970, caracterizada pelo milagre econômico, foi marcante nesse contexto em função da rápida expansão do parque industrial brasileiro. É importante lembrar que naquele período começavam a surgir os nossos 
primeiros órgãos ambientais, prevalecendo ainda dispositivos legais frágeis de proteção ambiental e certa precariedade no conhecimento dos impactos ecossistêmicos da poluição. As ações de fiscalização desses órgãos, quando ocorriam, baseavam-se em comando e controle, via aplicação de multas de valores geralmente irrisórios. Conjuntamente, todos esses fatores contribuíram para a criação de um quadro socioambiental complexo nas regiões metropolitanas, resultando em situações geradoras de conflitos ambientais. De um lado, a intensificação dos processos industriais acelerando a transformação de matéria e energia gerando cada vez mais poluição e, de outro, as reações da população. Na esteira da industrialização veio a rápida expansão das cidades, que motivou a especulação imobiliária desenfreada, deixando um legado de conflitos entre a urbanização e outros usos e ocupações do solo na periferia das metrópoles.

A partir da década de 1990 os problemas ambientais em todo o país se ampliaram e se diferenciaram daqueles das décadas de 1970 e 1980 que se relacionavam ao controle da poluição diretamente na fonte industrial. A promulgação da nova Constituição Federal em 1988 criou mecanismos de participação em licenciamentos de empreendimentos causadores de poluição e motivou uma crescente conscientização ecológica da população (Galvão Filho, 2001), além de maior percepção dos cidadãos como sujeitos portadores de direitos em situações envolvendo conflitos (Maciel, 2002). Nesse cenário, o Ministério Público ganhou projeção em iniciativas de defesa dos direitos difusos na área ambiental (Cunha, 2006). Por outro lado, a visibilidade propiciada pela institucionalização do meio ambiente como problema social e como tema de política pública delimitou uma nova arena de conflitos que, regida por instrumentos institucionais, legais e retóricos, passou a estruturar e legitimar os discursos, as ações e disputas entre grupos (Maciel, 2002).

$\mathrm{Na}$ atual fase da política ambiental brasileira observa-se um razoável nível de diálogo entre empresa, governo e sociedade organizada, de modo que esta passou a ter voz e a ser ouvida nos processos de concessão de licenças. Embora isso represente um inegável avanço em relação às práticas de aprovação de empreendimentos do passado, e tenha um propósito de minimizar impactos e conflitos ambientais, o que se constata na prática é que alguns processos de licenciamento se tornaram altamente conflituosos. Dito de outra forma, situações ou decisões que não encontraram bom respaldo da opinião pública passaram a ser revertidas ou retardadas por muito tempo, inclusive com o uso de ações judiciais (Cunha, 2006).

Revista de Gestão e Secretariado-GeSec, São Paulo, v. 7, n. 2, p 21-54,mai./ago. 2016. 


\section{Classificações por Tipologias}

Little (2001) considera os conflitos socioambientais como um campo de estudo e de ação política e os analisa sob a perspectiva da Ecologia Política. O Quadro 3 apresenta os tipos e respectivos subtipos propostos pelo autor.

Os subtipos específicos apresentados originaram-se de exemplos da experiência brasileira dos últimos anos e servirão de base para confronto e análise dos conflitos socioambientais urbanos encontrados na RMSP.

Quadro 3: Tipologias de conflitos socioambientais brasileiros

\begin{tabular}{|c|c|}
\hline Tipo & Subtipos \\
\hline \multirow{3}{*}{$\begin{array}{l}\text { 1) Conflitos em torno do controle } \\
\text { sobre os recursos naturais. }\end{array}$} & $\begin{array}{l}\text { a) A dimensão política é expressa por meio das disputas sobre a } \\
\text { distribuição dos recursos naturais. }\end{array}$ \\
\hline & $\begin{array}{l}\text { b) A dimensão social desses conflitos é expressa por meio das disputas } \\
\text { sobre o acesso aos recursos naturais. }\end{array}$ \\
\hline & $\begin{array}{l}\text { c) A dimensão jurídica desses conflitos é expressa por meio das disputas do } \\
\text { controle formal sobre os recursos. }\end{array}$ \\
\hline \multirow{3}{*}{$\begin{array}{l}\text { 2) Conflitos em torno dos impactos } \\
\text { ambientais e sociais gerados pela } \\
\text { ação humana e natural. }\end{array}$} & $\begin{array}{l}\text { a) Os casos de contaminação do meio ambiente são muitos e geram } \\
\text { impactos negativos diferenciados nas populações do meio ambiente onde } \\
\text { ocorre. }\end{array}$ \\
\hline & $\begin{array}{l}\text { b) O esgotamento dos recursos naturais também gera impactos } \\
\text { diferenciados nos grupos sociais, que não são fáceis de quantificar porque a } \\
\text { profundidade do impacto somente ficará em evidência no futuro. }\end{array}$ \\
\hline & $\begin{array}{l}\text { c) A degradação dos ecossistemas é vinculada aos processos de } \\
\text { contaminação e esgotamento, mas tem algumas particularidades. }\end{array}$ \\
\hline \multirow{3}{*}{$\begin{array}{l}\text { 3) Conflitos em torno do uso dos } \\
\text { conhecimentos ambientais. }\end{array}$} & $\begin{array}{l}\text { a) Os conflitos em torno de percepções de risco incrementam-se a cada dia } \\
\text { devido ao fato de que novas tecnologias estão produzindo impactos não } \\
\text { facilmente mensuráreis. }\end{array}$ \\
\hline & $\begin{array}{l}\text { b) Os conflitos sobre o controle formal dos conhecimentos ambientais } \\
\text { residem na figura legal da propriedade intelectual, que dá exclusividade ao } \\
\text { uso da informação apessoas ou ao grupo considerado como o criador ou } \\
\text { dono dessa informação. }\end{array}$ \\
\hline & $\begin{array}{l}\text { c) Os conflitos em torno de lugares sagrados colocam distintas } \\
\text { cosmovisões em choque. }\end{array}$ \\
\hline
\end{tabular}

Fonte: Elaborado pelos autores baseado em Little (2001).

O estudo em questão revelou cinco situações predominantes de conflitos ambientais na RMSP, relacionadas (i) à urbanização e à especulação imobiliária; (ii) à operação urbana; (iii) à ocupação irregular em áreas protegidas; (iv) a danos e passivos ambientais; e (v) à degradação de recursos hídricos, descritos como segue: 


\section{Relacionados à Urbanização e à Especulação Imobiliária}

O espaço urbano da RMSP é heterogêneo e marcado por fortes contradições sociais. Ao longo de décadas, o crescimento populacional e a falta de planejamento originaram uma situação de segregação sócio espacial, desfavorecendo os grupos com menores rendas. Devido à valorização excessiva dos imóveis que dispõem dos serviços básicos restaram à especulação imobiliária, as áreas periféricas e as ambientalmente frágeis (Silva, 2007). Inserem-se nessas categorias os sopés de morros, encostas, áreas de várzea, e estorno de áreas contaminadas por resíduos industriais. Maricatto (2003) destaca que os loteamentos e a ocupação dessas áreas por favelas e sub-habitações geram risco e em algumas situações, como nos entornos das represas Billings e Guarapiranga, ameaçam mananciais de abastecimento. A ocupação dessas áreas deve-se à grande demanda reprimida por habitação popular, ao baixo valor das terras, à cumplicidade do poder público e à fiscalização inoperante. Como agravantes, ela aponta a desarticulação existente entre os órgãos públicos estaduais e municipais e as políticas públicas metropolitanas de habitação, desenvolvimento industrial, energia e saneamento, dentre outras.

A maioria dos casos de conflitos entre urbanização e mineração no Estado de São Paulo está relacionada ao aproveitamento de minerais não metálicos, principalmente daqueles empregados diretamente na construção civil, como argilas para cerâmica vermelha e os agregados (areias de construção, cascalhos e britas) É interessante assinalar o paradoxo que se observa nesses conflitos, já que é o setor de construção civil (consumidor desses bens minerais) que está cerceando seu aproveitamento, à medida que a expansão urbana e as edificações avançam rumo às áreas de jazidas.

\section{Relacionados à Operação Urbana}

Um caso emblemático ilustrativo dessa categoria trata-se dos embates e negociações, descritos por Jacobi (1995), envolvendo o projeto de prolongamento da avenida Faria Lima, na gestão do prefeito Paulo Maluf, em São Paulo. Esse projeto denominado “Operação Urbana Faria Lima” alterava a ligação prevista até avenida Juscelino Kubitschek (prevista na Lei 7.104/68) e estendia seu raio de alcance até a avenida Luiz Carlos Berrini, local onde um dos maiores booms imobiliários da cidade havia ocorrido na década anterior.

Revista de Gestão e Secretariado-GeSec, São Paulo, v. 7, n. 2, p 21-54,mai./ago. 2016. 


\section{Segundo Jacobi (1995):}

[...]Enquanto o Poder Público tentava justificar a importância do projeto alegando que aliviaria o tráfego intenso na sua área de influência, surgiram movimentos organizados nos bairros da Vila Olímpia, Vila Funchal, Pinheiros e Itaim, visando organizar a resistência e estabelecer estratégias de ação conjunta. [...]Em março de 1993, esse movimento adota várias estratégias para impedir a viabilização do projeto. Inicialmente, ele faz injunções junto ao Conselho Estadual do Meio Ambiente (Consema) solicitando a exigência do Relatório de Impacto ao Meio Ambiente (RIMA) seja cumprida e, em seguida, articulando grupos de pressão com a população para pressionarem e monitorarem os trabalhos das comissões temáticas na Câmara Municipal. Simultaneamente organizavam também atividades para influir na formação da opinião pública visando orientar e informar os conselheiros membros do Consema a respeito dos efeitos nocivos à qualidade de vida que adviriam com o empreendimento. [...]Em seguida, o Movimento tenta através da revogação da Lei 7104/68, evitar que a Prefeitura inicie as demolições e inicie qualquer obra de extensão da Avenida Faria Lima. [...] Como consequência, a Prefeitura recua quanto à posição de iniciar as obras e a Avenida Faria Lima volta a ter o traçado previsto no projeto original de 1968 (Jacobi, 1995).

Na visão de Jacobi (1995), o debate sobre o Projeto Faria Lima, colocou em cena atores sociais que até então não tinham tido a experiência de se organizar com o objetivo de discutir ou se posicionar em relação às políticas públicas. Esses atores, pertencentes em sua maioria à classe média, viam esta problemática de forma distante, como sendo sempre daqueles que não possuíam alguma coisa específica, ou daqueles que lutam para ter direitos de moradia ou de acesso a serviços, tais como saúde e educação, creches e transportes. A luta pela preservação da qualidade de vida no espaço local foi o elemento que impulsionou esses cidadãos, até então distanciados do jogo político-reivindicatório, a se mobilizarem.

Ainda segundo Jacobi (1995), a articulação do Movimento contra o Projeto Faria Lima, colocou em cena atores que queriam preservar uma qualidade de vida consolidada e uma relação histórica de suas vidas com o local onde habitam. Ganhou visibilidade como um movimento que colocou na ordem do dia da cidade o questionamento sobre a ideia de progresso a qualquer custo, sem levar em conta o cidadão e sua identidade.

$\mathrm{O}$ referido autor destaca que o projeto trouxe à tona para esses setores bem aquinhoados da sociedade o despertar para a necessidade de influir na formulação das políticas públicas. A participação, mesmo que de início voltada apenas para a defesa de causas mais particularizadas, motivou outros setores das camadas das classes média e alta a se mobilizarem, procurando o Poder Público para discutir questões que viessem afetar sua qualidade de vida ou que pudessem interferir em seu cotidiano.

Jacobi (1995) acrescenta que o Movimento Faria Lima pode ser visto como exemplo, não só de um acúmulo de pequenas vitórias, mas também como um movimento que procurou inverter a lógica que alia uma Administração Municipal que faz das grandes obras 
públicas de alcances sociais muito duvidosos a grandes empreendedores e promotores imobiliários que sempre fizeram prevalecer os seus interesses particularizados.

\section{Relacionados à Ocupação Irregular em Áreas Protegidas}

Situação comum na periferia das metrópoles brasileiras é a ocupação irregular de áreas verdes protegidas por lei. Na RMSP, que é rodeada por resquícios de Mata Atlântica e mananciais, essa ocupação avançou sobre unidades de conservação, parques estaduais e municipais, reservas florestais e áreas de proteção ambiental. Os impactos ambientais decorrentes resultaram numa diversidade de situações conflituosas. É o que aconteceu em algumas porções do Parque Estadual da Cantareira, ao norte da cidade de São Paulo, em que mesmo com a existência de instrumentos legais visando conservação e de ações fiscalizadores do Estado, loteamentos clandestinos e construções irregulares avançaram sobre morros e encostas. Como agravantes, a supressão de vegetação abriu espaço para a disposição inadequada de resíduos sólidos, para a exploração irregular de recursos naturais e para a contaminação e assoreamento de corpos d'água com efeitos nefastos sobre a população do entorno.

Bernardelli Júnior, Ruiz e Gallardo (2014)analisou os conflitos socioambientais relacionados às interferências do Rodoanel Metropolitano na APA Bororé - Colônia dando destaque especial aos embates decorrentes da implantação do Parque Natural Municipal Itaim como medida compensatória dos impactos ambientais na referida APA. Dentre os principais conflitos, o autor destacou os seguintes: (i) externalidades negativas das obras incluindo assoreamento de corpos d’água, tráfego pesado afetando vias locais, desaparecimento de peixes; (ii) impossibilidade de utilização do anel viário pela população assentada na APA e seus entornos por se tratar de uma rodovia classe zero; (iii) poluição sonora e visual com viadutos passando nas portas das casas; (iv) deterioração das estradas vicinais existentes na APA devido a não cumprimento de acordo de compensação viária entre a Desenvolvimento Rodoviário S/A - Dersa e a Prefeitura Municipal; (v) inadequações no plantio compensatório de mudas de espécies nativas devido a insuficiência de áreas públicas para o plantio e problemas no próprio plantio e manejo subseqüente; e (vi) especulação imobiliária gerada pelos valores pagos pela Dersa nas desapropriações de terras para o Rodoanel e o Parque Itaim.

Revista de Gestão e Secretariado-GeSec, São Paulo, v. 7, n. 2, p 21-54,mai./ago. 2016. 
Bernardelli Júnior, Ruiz e Correa(2012) também analisaram os conflitos socioambientais relacionados aos processos de uso e ocupação do solo nos contrafortes da Cantareira destacando os relacionados à comercialização ilegal de lotes, construções irregulares, assentamentos precários em áreas públicas, disposição inadequada de resíduos, supressão de vegetação, exploração ilegal de recursos naturais, contaminação e assoreamento de corpos d'água, e intensificação do tráfego no local.

Berlinck, Caldas, Monteiro e Saito (2009) mencionam que esses conflitos refletem dilemas sociais entre interesses individuais e coletivos e que mesmo quando reconhecidos podem não ser considerados na elaboração dos planos de manejo das áreas protegidas. Os interesses individuais são os interesses frustrados dos cidadãos por habitação digna em função da demanda reprimida por moradias populares nas metrópoles. O interesse coletivo é o da conservação da floresta pela sua importância na prestação de serviços ambientais tais como: a regulação do fluxo e da qualidade da água dos mananciais, a proteção das escarpas e encostas, a conservação da fertilidade do solo, o controle climático, e o sequestro de $\mathrm{CO}_{2}$, dentre outros (Arce, Pendloski, Oliveira, Gallardo \& Ruiz, 2014; Bernardelli Júnior et al., 2012).

\section{Relacionados a Danos e Passivos Ambientais}

São diversos os casos de contaminações de solo e água oriundos de disposições irregulares de resíduos industriais (organoclorados, hidrocarbonetos, solventes orgânicos, borras de tintas, dentre outros) e de efluentes de composições variadas nos leitos e várzeas dos rios e córregos da RMSP. Muitas dessas contaminações, caracterizadas como passivos ambientais resultaram da poluição gerada anteriormente à década de 1980, quando a legislação sobre o assunto previa apenas tratamento de efluentes e emanações no fim do tubo (p. ex.: filtragem) antes de serem lançadas diretamente no meio ambiente. Como os mecanismos de fiscalização da época eram frágeis e as penalidades pouco rigorosas, essas disposições ocorriam em mananciais ou em terrenos situados nas imediações ou mesmo nos pátios das empresas geradoras dos efluentes e/ou resíduos.

Em 1981, a Política Nacional do Meio Ambiente (Lei n. 6.938, 1981) introduziu instrumentos de planejamento ambiental e passou a determinar a responsabilidade e penalidade para casos de poluição. A Resolução do Conselho Nacional do Meio Ambiente Conama $\mathrm{n}^{\circ} 420$ de 2009 apresentou critérios e valores orientadores de qualidade do solo no 
que se refere à presença de substâncias químicas estabelecendo também diretrizes para o gerenciamento ambiental das áreas contaminadas (decorrentes de atividades antrópicas). Temse ainda outros importantes diplomas legais, tais como, as Resoluções Conama 273 de 2000 e 307 de 2002. No âmbito Estadual, cita-se a Lei no 13.577 de 2009 que define diretrizes e procedimentos para a proteção da qualidade do solo e adequado gerenciamento de áreas contaminadas.

Como exemplo de dificuldades atuais na aplicação das leis, Antunes (2014), pontua que a legislação do estado de São Paulo apresenta ainda uma importante defasagem legal na aplicação de medidas punitivas. Conforme o autor, a Cetesb deixa de aplicar a Lei Estadual no 997 de 1976 para aplicar o Decreto Federal nº 6.514 de 2008 e Lei Federal no 9.605 de 1998.

[...]Quando existe uma ocorrência incidente de poluição industrial, sem qualquer base legal, a CETESB tem aplicado a Lei Federal 9.605/1998 e o seu regulamento administrativo estabelecido pelo Decreto Federal 6.514/2008. Alega a CETESB que a lei estadual está defasada no tempo e que a lei federal é mais condizente com a realidade atual. Entretanto, vale o registro de que a infração administrativa de poluição (artigo 61) no decreto federal é punida com multa variável entre R \$ 5.000,00 e R \$ 50.000.000,00[...] (Antunes, 2014)

Um caso emblemático de estocagem e comercialização de subproduto de processo produtivo que resultou num conflito ambiental de dimensão internacional é o da Solvay, localizada no município de Santo André. Informações do Greenpeace indicam que a empresa foi a responsável pela contaminação por dioxina detectada no leite, em março de 1998, na Alemanha. A contaminação se deu por meio do farelo de polpa cítrica importado do Brasil que foi utilizado como componente da ração usada na alimentação de gado leiteiro naquele país. Depois da realização de investigações e estudos, constatou-se que a cal vendida pela Solvay para ser misturada ao farelo e diminuir acidez, estava contaminada (Rossi, 1999). Devido à contaminação, a União Européia proibiu a importação do produto e obrigou a segregação de 100.000 t da cal que já havia sido importada (Federação das Indústrias do Estado de Santa Catarina, 2011).

Há casos em que vários produtos acabaram por contaminar o solo e as águas subterrâneas, ampliando ainda mais os problemas e conflitos socioambientais decorrentes. No bairro de Vila Carioca, por exemplo, uma área de aproximadamente $180 \mathrm{mil} \mathrm{m}^{2}$ foi contaminada pela Shell por benzeno, tolueno, xileno, etilbenzeno, metais tóxicos e organoclorados (aldrin, dieldrin e isodrin), com o comprometimento do lençol freático. A empresa foi multada pela Companhia Ambiental do Estado de São Paulo (CETESB) que

Revista de Gestão e Secretariado-GeSec, São Paulo, v. 7, n. 2, p 21-54,mai./ago. 2016. 
determinou que procedimentos fossem adotados para a delimitação da pluma de contaminação e tratamento da água (Araujo \& Gunther, 2009).

Marker (2008) destaca que o uso habitacional de áreas contaminadas pode colocar em risco os moradores do empreendimento imobiliário e consequentemente gerar conflitos de cunho legal e financeiro. Os impactos oriundos da contaminação para os moradores podem ocorrer de imediato ou ao longo de muitos anos, por meio de contato direto dos moradores com substâncias nocivas remanescentes no solo, pela utilização de água subterrânea contaminada, ou por via aérea, em consequência de gases nocivos emanados do subsolo. Um caso exemplar é o do Condomínio Barão de Mauá, localizado em área contaminada por produtos químicos da empresa Cofap (Olivette, 2003).

\section{Relacionados à Degradação de Recursos Hídricos}

A distribuição desigual da água no espaço e na sociedade produz situações de escassez relativa e pode resultar em conflitos relacionados à sua apropriação. Em se tratando de um bem de uso comum, os conflitos nas regiões metropolitanas geralmente decorrem do seu uso para criação de valor e da perda de valor decorrente de sua degradação por poluição (Fracalanza, 2002).

Um exemplo de conflitos relacionados à criação e à perda de valor com os usos da água refere-se aos registrados no Reservatório Billings, determinados pela mudança no regime de fluxo, em períodos distintos, como pode ser visto no Quadro 4. Este conflito existe em função de interesses contrapostos, porém, legítimos, desde a implantação do reservatório até pelo menos o início deste milênio.

Quadro 4: Conflitos relacionados à criação do Reservatório Billings e à mudança do fluxo de água ao longo dos anos.

\begin{tabular}{|l|l|l|}
\hline Período & Situação & Conflitos \\
\hline $1927-1949$ & $\begin{array}{l}\text { Formação do reservatório para geração de } \\
\text { energia elétrica na Usina Henry Borden. }\end{array}$ & $\begin{array}{l}\text { Necessidade de geração de energia elétrica } \\
\text { para manutenção das atividades industriais } \\
\text { em Cubatão versus proprietários fundiários } \\
\text { das áreas alagadas e dos entornos do } \\
\text { reservatório. }\end{array}$ \\
\hline
\end{tabular}

Revista de Gestão e Secretariado-GeSec, São Paulo, v. 7, n. 2, p 21-54,mai./ago. 2016. 


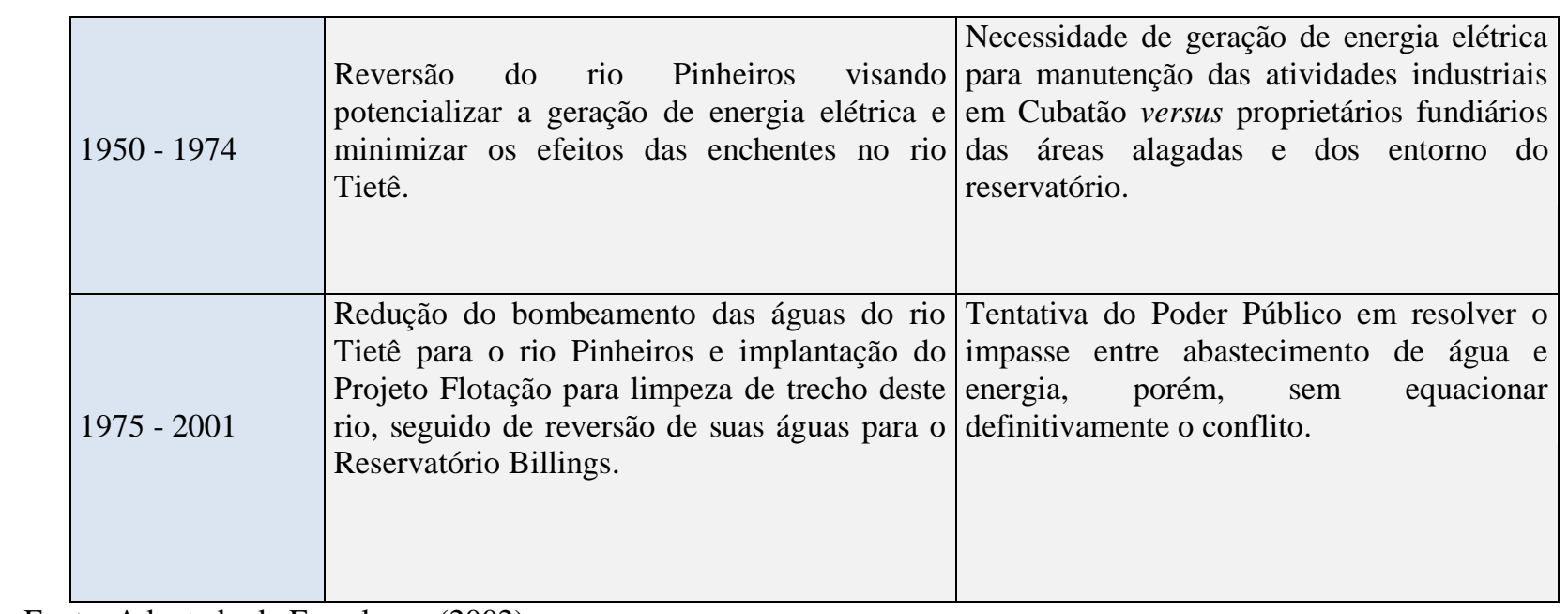

Fonte: Adaptado de Fracalanza (2002).

Conflitos decorrentes da ocupação irregular e degradação de áreas de proteção de mananciais durante a gestão municipal da prefeita Luiza Erundina entre 1989 e 1993 são reportados por Villas Boas (1995). Segundo esta autora:

[...]desde a implantação da Lei Estadual de Proteção dos Mananciais em São Paulo, em 1976, o Estado privilegiou o parâmetro ambiental em suas diretrizes de atuação, sem enfrentar o problema da ausência de saneamento e do déficit habitacional na Grande São Paulo. Essa legislação, de caráter exclusivamente preservacionista, resultou na desvalorização de terras na área de mananciais atraindo o mercado informal de loteamentos clandestinos e favorecendo a ocupação da população de baixa renda no local. Tal situação foi agravada pelo fato da região sul do município ter se tornado um polo industrial e comercial que concentrou uma das maiores ofertas de emprego da cidade (Villas Boas, 1995).

Partindo de uma visão inovadora de descentralização das ações governamentais e de interlocução com vários grupos sociais que atuavam na região dos mananciais, para a construção de alianças visando a implementação de políticas de preservação ambiental, a gestão da prefeita Erundina fez vir à tona conflitos socioambientais preexistentes que envolviam uma multiplicidade de atores. Dentre esses atores destacam-se representantes dos movimentos ambientalistas, dos movimentos populares de moradia e de órgãos governamentais dedicados à questão (Villas Boas, 1995).

Uma situação exemplar de conflitos socioambientais dessa natureza é o da ocupação irregular de moradias nos entornos dos reservatórios Guarapiranga e Billings descrita por Jacobi (1995). Assim, segundo esse autor:

[...]isto nos remete à questão da ausência de políticas habitacionais para a população de baixa renda e à incapacidade do Poder Público em conter a especulação imobiliária inescrupulosa em áreas que estão sob sua responsabilidade legal. Este caso traz à tona o conflito existente entre o discurso dos que ocupam e moram nessas áreas protegidas por lei estadual, com o discurso preservacionista, que prioriza sua atuação no 
intuito de evitar, reprimir ou até mesmo remover novas ocupações (Jacobi, 1995).

A perda de valor da água em função da degradação por poluição decorre do aumento de custos de tratamento visando o abastecimento público e industrial, situação cada vez mais frequente em áreas densamente povoadas. Esta situação na RMSP, somada à demanda crescente de água pela população, tem feito com que cerca de $50 \%$ do abastecimento sejam provenientes da transposição de água oriunda da bacia dos rios Piracicaba, Jundiaí e Capivari (PCJ) via o Sistema Cantareira(Moretti \&Gontijo Júnior, 2005).

Em 2004, depois de um conflito judicial, envolvendo a Agência Nacional de Águas (ANA), o Comitê do PCJ, o Departamento de Águas e Energia Elétrica (Daee), e a Companhia de Saneamento Básico do Estado de São Paulo (Sabesp), foi renovada a outorga do Sistema Cantareira garantindo o suprimento à RMSP. Em agosto de 2014, quando venceria a outorga, em função da crise hídrica que se abateu sobre o Sudeste do país, expressa pelos valores mais baixos de vazão de afluentes desde o ano de 1930, o prazo de vigência da outorga de direito de uso de recursos hídricos do referido Sistema para a Sabesp foi prorrogado duas vezes, sendo a primeira para 31 de outubro de 2015 e a segunda para 31 de maio de 2017 (Agência Nacional de Águas, n.d.).

\section{Análise Agregada dos Conflitos Existentes na RMSP}

Observa-seque as cinco categorias de conflitos apresentadas estão interligadas em torno da questão da expansão urbana em direção às áreas periféricas ou às franjas metropolitanas. Ao confrontar as cinco tipologias de conflitos aqui apresentadas para a RMSP com as três tipologias da classificação de Little (2001),verifica-se que todos os embates ambientais detectados na RMSP, respectivamente relacionados à urbanização periférica e desigual, a operação urbana de expansão de grande avenida, à degradação de recursos hídricos, e a passivos e danos ambientais se relacionam mais diretamente com a tipologia "conflitos em torno dos impactos ambientais e sociais gerados pela ação humana e natural. No que tange a esta categoria delineada por Little, ele destaca que:

A intervenção humana nos ciclos naturais nos processos para ganhar sustentação e desenvolvimento econômico gera muitos impactos que são nefastos tanto para o funcionamento da natureza em si quanto para seres humanos. Além do mais, muitas vezes os grupos sociais que fazem as intervenções e recebem benefícios diretos delas não sofrem dos impactos negativos disso, enquanto outros grupos que não

Revista de Gestão e Secretariado-GeSec, São Paulo, v. 7, n. 2, p 21-54,mai./ago. 2016. 
recebem nenhum benefício sofrem diretamente com o processo. Assim, essas situações provocam problemas tanto pelas ameaças à saúde dos afetados quanto pela injustiça da ação (Little, 2001, p.111).

Adicionalmente, pode-se dizer que os conflitos inseridos nesta categoria de Little (2011) têm relação com injustiças ambientais nos moldes apresentados nos conceitos apresentados pelo Instituto Brasileiro de Análises Sociais e Econômicas (2003); Acselrad, (2004); e Costa (2011).

\section{Mecanismos de Tratamento e Gestão}

Os conflitos advindos da crescente concentração populacional aliados a um modelo de desenvolvimento econômico que compromete o equilíbrio ecológico e, consequentemente, a qualidade de vida dos cidadãos, têm gerado demandas judiciais cada vez mais complexas envolvendo questões ambientais (Araújo, 1999).

A gestão de conflitos socioambientais no Brasil ainda se apóia fortemente em instrumentos judiciais, o que tem resultado em grande acúmulo de processos no Judiciário. Porém, Bredariol (2004) destaca que na esfera da política ambiental há uma forte tendência em se estabelecer a gestão ambiental com base em mecanismos tripartites envolvendo Estado, Mercado e Sociedade, onde as palavras de ordem são parceria e negociação.

Um importante instrumento de solução de conflitos socioambientais na esfera jurisdicional é a ação civil pública. Esta ação é proposta pelo Ministério Público ou outros entes legitimados (pessoas jurídicas públicas ou privadas) que visam proteger o patrimônio público e social, o meio ambiente, enfim, quaisquer direitos difusos e coletivos. Sua utilização tem sido frequente em situações envolvendo danos e passivos ambientais em regiões metropolitanas e outras áreas densamente ocupadas.

Araújo (1999) destaca que com a instituição da Lei da Ação Civil Pública em 1985, os conflitos socioambientais levados a juízo tanto cresceram em quantidade quanto em complexidade técnica, a ser absorvida e solucionada pelo Poder Judiciário.

Outro instrumento frequentemente utilizado na solução de conflitos socioambientais é o Termo de Ajustamento de Conduta (TAC). A aplicação deste instrumento vem crescendo porque o modelo jurídico e institucional vigente, baseado na punição dos infratores, mediante a aplicação de sanções penais, civis e administrativas, não tem se mostrado adequado e plenamente eficaz para proteger os direitos difusos, especialmente o

Revista de Gestão e Secretariado-GeSec, São Paulo, v. 7, n. 2, p 21-54,mai./ago. 2016. 
direito ao meio ambiente ecologicamente equilibrado. O TAC estabelece obrigações e condicionantes técnicos que devem ser rigorosamente observados pelos infratores em relação à atividade causadora da degradação de modo a fazer cessar, adaptar, recompor, corrigir ou minimizar seus efeitos negativos sobre o meio ambiente (Miranda, 2011).

Alguns instrumentos de gestão ambiental implantados por órgãos públicos, mas que na prática não têm gerado resultados satisfatórios em regiões metropolitanas, referem-se à criação de unidades de conservação e áreas de proteção ambiental envolvendo remanescentes de florestas e nascentes. O mesmo pode ser dito a respeito das iniciativas de planos diretores específicos voltados para o ordenamento de atividades industriais e a minimização da incidência de conflitos ambientais. É exemplar o caso do Plano Diretor de Mineração da RMSP, elaborado nas décadas de 1970 e 1980, pela Empresa Paulista de Planejamento Metropolitano (Emplasa) e o Departamento Nacional da Produção Mineral (DNPM), visando garantir a continuidade da produção mineral nos seus municípios. Em função da desarticulação das políticas públicas, essa iniciativa não chegou a ser efetivamente implantada.

As iniciativas de gestão ambiental nas empresas também têm se revelado importantes para a redução da incidência de conflitos socioambientais(Galvão Filho, 2001). As medidas que adotam geralmente têm caráter jurídico/normativo envolvendo o licenciamento ambiental, gestão baseada na série ISO 14.000 e Responsabilidade Social Empresarial (ISO 26.000).

Bobbio, Matteucci\& Pasquino, (1986) destacam que na gestão dos conflitos a eliminação completa das causas, tensões e contrastes que os originam é relativamente rara. $\mathrm{O}$ processo ou tentativa mais frequente é o de proceder à formulação de regras aceitas pelas partes envolvidas para que se estabeleçam determinados limites de ganhos e perdas. O ponto crucial é que as regras devem ser aceitas por todos os participantes e, se mudadas, devem ser por recíproco acordo. Nesta linha, Susskind e Field (1997) enfatizam que a administração dos conflitos visando sua resolução por via pacífica pode apoiar-se na abordagem dos ganhos mútuos, que propõe a ultrapassagem de um padrão de jogos de soma zero, aqueles em que um lado ganha e o outro perde, e os resultados positivos e negativos anulam-se no balanço total.

A negociação de conflitos socioambientais é uma área de crescente importância face às dificuldades inerentes aos processos de gestão, às inovações introduzidas na legislação brasileira desde a promulgação da Constituição de 1988, e às demandas do processo global de 
construção da sustentabilidade (Cunha, 2006). A emergência do assunto provavelmente explique a afirmação de Bedrariol (2004) de que a literatura brasileira sobre negociação de conflitos socioambientais ainda é pobre.

A Resolução Conama 001/86, que instituiu os procedimentos de estudos de impactos ambientais (EIA) e a análise dos riscos, para todas as atividades modificadoras do meio ambiente, também introduziu as audiências públicas como fórum de debate entre as partes com interesse local sobre os aspectos jurídicos e técnicos do empreendimento em questão.

Segundo Camargo (2007), nos EUA, Canadá e em alguns países europeus, já se observam tendências para solução negociada de conflitos ambientais, via mediação. Segundo ela, embora o direito ambiental verse sobre os direitos indisponíveis, um de seus princípios é o da participação que preconiza o envolvimento dos cidadãos, individual ou coletivamente, para a formulação e execução da política ambiental, e garante a transparência das decisões e a participação efetiva de todos. Cabe destacar, no entanto, que as negociações via mediação somente têm sido possíveis no campo dos direitos individuais (pessoas envolvidas), mas não na esfera dos direitos transindividuais ou coletivos em função da ampla gama de interesses envolvidos.

Nesse sentido, a mediação se apresenta como uma importante ferramenta para a solução negociada de conflitos socioambientais no Brasil, em anos vindouros, pelo fato de minimizar os custos ao reduzir o número de reuniões das audiências públicas e apresentar alto nível de cumprimento.

Gerasidi, Apostolaki, Manoli, AssimacopoluloeVlachos(2009), a partir de dificuldades de planejamento relacionadas ao planejamento e gestão de recursos hídricos em ambiente urbano na Costa do Mediterrâneo, enfatiza que o envolvimento dos stakeholders em soluções negociadas nesses processos é tido como um importante fator de sucesso, particularmente quando os esforços são direcionados para a resolução de conflitos em áreas com escassez de água. Segundo esses autores, o envolvimento dos stakeholders possibilita: a) o melhor entendimento das diferentes partes interessadas nos problemas relativos ao gerenciamento da água; b) a articulação mais clara do contexto dos acordos e desentendimentos; e c) contribuir de forma significativa para o gerenciamento e a resolução do conflito.

Revista de Gestão e Secretariado-GeSec, São Paulo, v. 7, n. 2, p 21-54,mai./ago. 2016. 


\section{CONSIDERAÇÕES FINAIS}

Em resposta à questão de pesquisa “quais as origens dos principais conflitos socioambientais que se manifestam na Região Metropolitana de São Paulo e como eles podem ser classificados e analisados à luz da literatura existente”, pode-se concluir que os conflitos socioambientais urbanos são frequentes nas regiões metropolitanas industrializadas, com destaque para a RMSP, onde a ocupação do espaço se deu a uma velocidade acelerada, praticamente à revelia da legislação e dos mecanismos de planejamento existentes. As formas de ocorrência e de manifestação desses conflitos são diversas e dependem do contexto urbano em que se inserem.

A preocupação com a gestão dos conflitos socioambientais no ambiente urbano e suas imediações existe há décadas, porém ganhou mais relevância a partir da promulgação da Constituição Federal de 1988.

A gestão ambiental empresarial, o licenciamento ambiental, o zoneamento, e a implantação de unidades de conservação e de áreas de proteção ambiental destacam-se como medidas preventivas ou atenuadoras dos conflitos socioambientais. No entanto, como esses embates geralmente se dão num plano político, geralmente envolvendo ações ou omissões do poder público, suas resoluções nem sempre acabam acontecendo, sendo frequentes as reclamações das partes menos favorecidas.

A mediação começa a despontar como técnica com potencial de uso futuro por parte de órgãos ambientais, Ministério Público e outras partes interessadas na solução desses conflitos. No entanto, além da necessidade de formação de mediadores ambientais, outros desafios importantes que se colocam para a nossa sociedade referem-se à viabilização de treinamentos para formação de facilitadores de diálogo, e de organizadores/coordenadores de fóruns participativos e de parcerias colaborativas.

Como os conflitos socioambientais urbanos ainda são pouco explorados de forma organizada na literatura, como estudo futuro recomenda-se a realização de um mapeamento e sistematização das informações desses embates na RMSP, o qual poderá ser de grande valia para gestores ambientais, formuladores de políticas públicas, promotores e juízes. Além disso, como a maioria desses conflitos quando evidenciados acabam sendo alvo de ações civis públicas e resolvidos no âmbito do Judiciário, um estudo complementar sobre a judicialização desses embates e uma avaliação preliminar de que outras formas de negociação seriam 
possíveis visando suas implementações no futuro também seria de grande valia.

Adicionalmente também há expectativas de que as câmaras de mediação de pequenas causas que vêm emergindo atualmente possam despontar como embriões de futuros fóruns para discussão e encaminhamento de soluções para alguns tipos de conflitos ambientais típicos de regiões metropolitanas como a de São Paulo. Isso não somente propiciaria uma nova forma de dar vazão a várias situações que são apresentadas por partes afetadas ao Ministério Público como ajudaria a aliviar a sobrecarga de ações civis públicas junto ao Judiciário.

\section{REFERÊNCIAS}

Acselrad, H. Introdução. In: Acselrad, H. (Org.). (2004). Conflitos ambientais no Brasil. Rio de Janeiro: Relume Dumará, São Paulo, pp. 32-42.

Agência Nacional de Águas. (n.d.). Renovação da Outorga do Sistema Cantareira. $\begin{array}{lllll}\text { Recuperado em } & 1 & \text { de } & \text { junho, }\end{array}$ http://www2.ana.gov.br/Paginas/servicos/outorgaefiscalizacao/renovacaocantareira.aspx

Alonso, A.\& Costa, V. (2002). Por uma Sociologia dos conflitos socioambientais no Brasil. Ecología Política: naturaleza, sociedad y utopía. [S. 1.]: CLACSO. Recuperado em 5 setembro, 2011, de: 〈http://bibliotecavirtual.clacso.org.ar/ar/libros/ecologia/alonso.pdf〉.

Antunes, P. de B. (2014, 21 de dezembro). São Paulo precisa esclarecer critérios de aplicação das leis ambientais. Consultor Jurídico, São Paulo, SP. Recuperado em 9 agosto, 2016, de http://www.conjur.com.br/2014-dez-21/paulo-antunes-sao-paulo-corrigir-politicaambiental.

Araújo, L. A. (1999). Perícia ambiental em ações civis públicas. In S. B. Cunha \& A. J. T. Guerra (orgs.). Avaliação e perícia ambiental. (pp. 174-215). Rio de Janeiro: Bertrand Brasil.

Araujo, J. M, \& Günther, W. M. R. (2009). Riscos à saúde em áreas contaminadas: contribuições da teoria social. Saúde e sociedade, 18(2) 312-324.

Arce, P., Pendloski, C. J. S., Oliveira, R. B., Gallardo, A. L. C. F., Ruiz, M. S. (2014). Conflitos socioambientais em Unidades de Conservação em áreas urbanas: O caso do Parque Tizo em São Paulo. Holos (Natal. Online), vol. 30, pp. 75-85.

Baechler, G. (1998). Why environmental transformation causes violence. Environmental Change and Security Project Report, 4, 24-44.

Bastos, A.C. S.\& Freitas, A. C. (1999). Agentes e processos de interferência, degradação e dano ambiental. In S. B. Cunha \&A. J. T. Guerra (orgs.). Avaliação e perícia ambiental. Rio

Revista de Gestão e Secretariado-GeSec, São Paulo, v. 7, n. 2, p 21-54,mai./ago. 2016. 
de Janeiro: Bertrand Brasil, pp. 17-75.

Bauer, A. R., Trent, B. A.\& Dumontelle, P.(2006).Mine subsidence: facts or homeowners. Environmental Geology. n. 144, Illinois State Geological Survey, Champaign, IL.

Berlinck, C., Caldas, A., Monteiro, A. \& Saito, C. (2009). Contribuição da educação ambiental na explicitação e resolução de conflitos em torno dos recursos hídricos. Ambiente $e$ Educação, 8(1), 117-129.

Bernardelli Júnior, J. M. (2013). Conflitos socioambientais urbanos na APA Bororé Colônia: O caso do Parque Natural Municipal Itaim. Dissertação de mestrado, Universidade Nove de Julho, São Paulo.

Bernardelli Júnior, J. M., Ruiz, M. S. \& Correa, R. (2012). Conflitos socioambientais urbanos: caracterização e análise dos embates relacionados ao adensamento humano rumo aos contrafortes da Cantareira. In: Encontro Nacional de Pesquisadores, 6, 2012, São Paulo. Anais.... São Paulo: PUC, 2012, pp. 1-17.

Bernardelli Junior, J. M., Ruiz, M. S. \& Gallardo, A. L. C. F. (2014). Contribuição metodológica para a análise de conflitos sócio ambientais a partir do caso do trecho sul do rodoanel, São Paulo/SP.Anais do Encontro Nacional sobre Gestão Empresarial e Meio Ambiente, São Paulo, SP, Brasil, 16.

Bobbio, N., Matteucci, N. \& Pasquino, G. (1986).Dicionário de política(2a ed.).Brasília: Editora da UnB.

Braga Neto, A. (2011). Mediação de conflitos e políticas públicas - a experiência com a mediação comunitária em distritos de alta vulnerabilidade da Grande São Paulo. Rio Grande: Âmbito Jurídico.Recuperado em 27 junho, 2011, de <http://www.ambitojuridico.com.br/site/index.php?n_link=revista_artigos_leitura\&artigo_id=4230>.

Bredariol, C. S. (2004). O aprendizado da negociação em conflitos ambientais. Anais do Encontro Nacional de Pós-Graduação e Pesquisa em Ambiente e Sociedade, Indaiatuba, SP, Brasil, 2. Recuperado em 27 junho, 2011, de: <http://www.anppas.org.br/encontro_anual/encontro2/GT/GT17/gt17_celso_bredariol.pdf>.

Camargo, S. (2007). Mediação ambiental. Jornal do Instituto de Engenharia, 4(39).

Carvalho, R. C. (2005). Gestão dos recursos hídricos: conflito e negociação na questão das águas transpostas da Bacia do Paraíba do Sul.Tese de doutorado, Universidade Federal do Rio de Janeiro, Rio de Janeiro, RJ, Brasil.

Castro, F. (2009). Urbanização dispersa e mudanças no tecido urbano: Estudo de caso: Estado de São Paulo. São Paulo: Agência FAPESP.

Cervo, A. C.\& Bervian, P. A. (1996). Metodologia científica(4a ed.). São Paulo: Makron.

Revista de Gestão e Secretariado-GeSec, São Paulo, v. 7, n. 2, p 21-54,mai./ago. 2016. 
Cimba lista, S. N.(2002). Temas especiais: A influência da tecnologia na geração de conflitos no trabalho. Análise Conjuntural, 24(9-10), [S. 1.]. Recuperado em 19 janeiro, 2012, de <http://www.ipardes.gov.br/biblioteca/docs/bol_24_5d.pdf>.

Côrtes, P. L., Alves Filho, A. P., Ruiz, M. S., Teixeira, C. E. (2011). A deposição de resíduos industriais organoclorados no litoral do Estado de São Paulo: um estudo de caso. RAI: Revista de Administração e Inovação, vol. 8, pp. 133-163.

Costa, G. V. L. (2011). As reservas biológicas como mecanismo de controle estatal. Revista de Sociologia e Política,19(38),159-170.

Coulon, F. K. (1990). Fenômeno de subsidência: Acidente em Criciúma - SC.Anais do Simpósio Sobre Risco Geológico Urbano. São Paulo, SP, Brasil, 1.

Cunha, I. A. (2006). Oficina de negociação ambiental - material de apoio. Curitiba, PR, Brasil.

. (2001). Conflito ambiental na costa de São Paulo: o Plano Diretor de São Sebastião. Saúde e Sociedade, 10(1),15-31.

Dahrendorf, R. (1963). Classi e conflitto di classe nella società industriale. Bari: La terza.

Dias, G. F. (2000). Educação ambiental princípios e práticas. São Paulo: Gaia, 2000.

Dolan, R.\&Goodel, H. G. (1986). Sinking cities. American Scientist, (74).

Dumontelle, P. B.,Bradford, S. C.,Bauer, R. A. \& Killey, N. B. (1981). Mine subsidence in Illinois: facts for the homeowner considering insurance. Environmental Geology Notes. N. 99, Illinois State Geological Survey, Champaign, IL.

Federação das Indústrias do Estado de Santa Catarina - Fiesc. [S. 1.]. Solvay terá de descontaminar depósito de cal contaminada por dioxina em Santo André (SP).FIES Cnet. Florianópolis. Recuperado em 14 junho, 2011, de < http://www.fiescnet.com.br/gestaoambiental/noticias/9-solvay.htm>.

Formosinho, S. J., Pio, C. A.,Barros, J.H.\&Cavalheiro, J.R. Parecer relativo ao tratamento de resíduos industriais perigosos. Recuperado em 18 maio, 2002, de <http://www2.ufp.pt/ madinis/HPSA/Rcom.pdf>.

Fracalanza, A. P. (2002, novembro). Reservatório Billings: apropriação da água, conflitos e gestão. Anais do Encontro Nacional de Pós-graduação e Pesquisa em Ambiente e Sociedade, Indaiatuba, SP, Brasil, 1.

Freitas, C. M. de,Porte, M. F. de S.\&Gomez, C. M.(1995). Acidentes químicos ampliados: um desafio para a saúde pública. Revista de Saúde Pública,29(6),503-514.

Fuks, M. (1997). Arenas de ação e debate públicos: os conflitos socioambientais e a 
emergência do meio ambiente enquanto problema social no Rio de Janeiro (1985-1992).Tese de Doutorado, Instituto Universitário de Pesquisas do Rio de Janeiro, Rio de Janeiro, RJ, Brasil.

Galvão Filho, J. B. (2001). A gestão de conflitos socioambientaisno uso dos recursos naturais. Revista Banas Ambiental, 2(11). Recuperado em 20 junho, 2011, de < http://www.consultoriaambiental.com.br/artigos/a_gestao_de_conflitos_ambienteais_no_uso_ dos_recursos_naturais.pdf >.

Gerasidi, A., Apostolaki, S.,Manoli, E.,Assimacopolulo, D.\& Vlachos, E. (2009). Towards the formulation of a new strategy of water resource management for urban areas achieved through participatory process. Urban Water Journal, 6(3), 2009-2019.

Gil, A. C. (1995). Como elaborar projetos de pesquisa(3a.ed.).São Paulo: Atlas.

Hannigan, J. (1995). Environmental sociology: a social constructionist perspective.London: Routledge.

IBGE (2010). Censo demográfico: População residente por situação do domicílio e a localização da área, segundo as Regiões Metropolitanas, as Regiões Integradas de Desenvolvimento - Rides, Os municípios e o sexo - 2010. Rio de Janeiro: IBGE, 2011. Recuperado em agosto, $2016 \quad$ de http://www.ibge.gov.br/home/estatistica/populacao/censo2010/sinopse_tab_rm_zip.shtm.

Instituto Brasileiro de Análises Sociais e Econômicas (2003). Descortinando o Brasil: justiça ambiental. Rio de Janeiro: IBASE / FASE / IPPUR.

Jacobi, P. R. (2006). Impactos socioambientais urbanos na Região Metropolitana de São Paulo. Revista Eletrônica Vera Cidade,1(1), 1-12.

Jacobi, P. R. (1995). Diagnóstico de conflitos socioambientais na cidade de São Paulo. Cadernos Cedec n. 45. São Paulo: Centro de Estudos de Cultura Contemporânea - Cedec.

Kowarick, L.\&Marques, E. (2012). São Paulo: novos percursos e atores (sociedade, cultura e política).Centro de Estudos da Metrópole. São Paulo.

Lakatos, E. M.\&Marconi, M. A. (2007). Metodologia científica(5a. ed.). São Paulo: Atlas.

Laschefski, K.\&Costa, H. S. M. (2008). Segregação social como externalização de conflitos ambientais: a elitização do meio ambiente na APA-Sul, Região Metropolitana de Belo Horizonte. Ambiente e Sociedade, 11(2), 307-322.

Little, P. E. (2004, maio).A etnografia dos conflitos socioambientais: bases metodológicas e empíricas. Anais do Encontro Nacional de Pós-graduação e Pesquisa em Ambiente e Sociedade, Indaiatuba, SP, Brasil, 2. Recuperado em 20 julho, 2009, de <http://www.anppas.org.br/encontro_anual/encontro2/GT/GT17/gt17_little.pdf>. 
(2001). Os conflitos socioambientais: um campo de estudo e de ação política. In Bursztyn, M. (Org.). A difícil sustentabilidade - política energética e conflitos ambientais Rio de Janeiro: Garamond,107-122

Maciel, D. A. (2002). Ministério público e sociedade a gestão de conflitos socioambientais em São Paulo. Tese de Doutorado, Faculdade de Filosofia da Universidade de São Paulo, São Paulo, SP, Brasil.

Maricato, E. (2003). Metrópole, legislação e desigualdade. Estudos Avançados, 17 (48), $\begin{array}{lllll}\text { Recuperado em } & 02 & \text { abril, } & 2009,\end{array}$ $<$ http://www.scielo.br/scielo.php?script=sci_arttext\&pid=S0103-

$40142003000200013 \& \operatorname{lng}=$ en\&nrm=iso>.

Marker, A. (2008). Avaliação ambiental de terrenos com potencial de contaminação: gerenciamento de riscos em empreendimentos imobiliários. Guia caixa: sustentabilidade ambiental. Brasília: CEF-DF.

Matthew, R. A.;Gaulin, T. \& McDonald B. (2003). The elusive quest: linking environmental

change and conflict. Canadian Journal of Political Science / Revue Canidiense de Science Politique, 36 (4), 857-878.

Mavrolas, P. \& Schechtman, M. (1981). Coal mining subsidence. Proceedings of citizen's conference, Herrin, IL,USA, 2.

Meyer, R. M. P. (2004). São Paulo metrópole. São Paulo: Edusp.

Miranda, A. (2011). Mecanismos de compromisso de ajuste. Belo Horizonte: Ietec. Recuperado em 7 setembro, 2011, de <http:// www.ietec.com.br/site/techoje/>.

Moretti, L. R. \&GontijoJúnior, W. C. (2005, novembro). Conciliação de conflito dentro da política brasileira de recursos hídricos - o caso do Sistema Cantareira. Anais do Simpósio Brasileiro de Recursos Hídricos, João Pessoa, PB, Brasil, 16.

Negri, B. (1996). Concentração e desconcentração industrial em São Paulo (1880 1990).Campinas, SP: Editora da Unicamp.

Nickum, J. \& Easter, K. W. (1994) Metropolitan water use conflicts in Asia and the Pacific. Westview Press Studies in Water policy and Management / The East - West Center Program on Environment, Boulder, CO.

Nobre, C. A., Young, A. F., Saldiva, P., Nobre, A. D., Silva G. C. M. da, Lombardo, M. (2010). Vulnerabilidades das megacidades brasileiras às mudanças climáticas:Região Metropolitana de São Paulo. (Sumário Executivo). São Paulo.

Revista de Gestão e Secretariado-GeSec, São Paulo, v. 7, n. 2, p 21-54,mai./ago. 2016. 
Olivette (2003). Cetesb acompanha coleta no Condomínio Barão de Mauá. Recuperadoem 12 de outubro, 2009, de http://www.CETESB.sp.gov.br/Noticias/003/10/29 barao_maua.asp.

Bobbio, N., Matteucci, N.\& Pasquino, G. (1986). Dicionário de política (2a ed.). Brasília: Universidade de Brasília.

Phillips, A. S., Hung, Y-T. \&Bosela, P. A. (2007). Love Canal Tragedy. Journal of Performance of Constructed Facilities, Nova York, 21 (4), 313-319.

Ritter, L., Solomon, K.R.\& Forget, J. (1995). A Review of selected persistent organic pollutants. Guelph: International Programme on Chemical Safety. Recuperadoem 27 outubro, 2009, de <http://www.who.int/ipcs/assessment/en/pcs_95_39_2004_05_13.pdf>.

Rossi, C. SP tem maior depósito de cal contaminada (1999). Folha de São Paulo. 19 de junho de 1999. Recuperado em 6 de agosto de 2016, de https://www.google.com.br/webhp?sourceid=chrome-instant\&rlz=1C1CHVZ_pt-

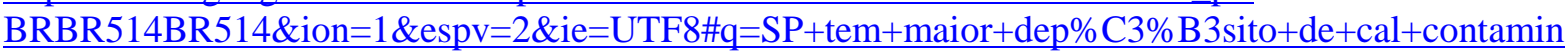
ada.

Ruiz, M. S., Correa, R., Gallardo, A. \& Sintoni, A. (2014).Abordagens de conflitos socioambientais em casos de subsidência de minas de carvão no Brasil e EUA. Revista Ambiente e Sociedade,17(2), 129-156.

Ruiz, M. S., Yu, A. S. O., Martins, F. E.\& Goncalves, L. R. (2012). Tecnologias de remedição de áreas contaminadas com organoclorados: uma avaliação preliminar visando possíveis aplicações no sítio da rua Cápua, Santo André? SP.Revista de Gestão Ambiental e Sustentabilidade, vol. 1, pp. 103-125.

Severino, A. (2007). Metodologia do trabalho científico.São Paulo: Cortez.

Silva, K. O. (2007). A periferização causada pela desigual urbanização brasileira. Revista Urutágua,11, 1-8.

Susskind, L. \& Field, P. (1997). Em crise com a opinião pública: o diálogo como técnica fundamental para solucionar disputas. São Paulo: Futura.

UN-United Nations, Department of Economic and Social Affairs, Population Division (2015). World Urbanization Prospects: The 2014 Revision, (ST/ESA/SER.A/366).

Valverde, F. M. \& Kiyotani, M. A. (1986). Mineração em áreas urbanas. Brasil Mineral,4, (30), 31-36.

Villas Boas, R. (1995). São Paulo: conflitos e negociações na disputa pela cidade. São Paulo: Polis.

Wentz, C. A. (1995). Hazardous waste management. Nova York: McGraw-Hill. 
Westman, W. E. (1985). Ecology, impact assessment and environmental planning. New York: John Wiley \& Sons.

Revista de Gestão e Secretariado -GeSec, São Paulo, v. 7, n. 2, p 21-54,mai./ago. 2016. 